\title{
Ontogeny of L-Alanine Uptake in Plasma Membrane Vesicles from Rat Liver
}

\author{
MERCÈ AMAT, ANTONIO FELIPE, JAVIER CASADO, AND MARÇAL PASTOR-ANGLADA \\ Unitat de Bioquímica i Biologia Molecular B, Departament de Bioquímica i Fisiologia, Universitat de \\ Barcelona, Avda Diagonal, 645, 08028 Barcelona, Spain
} \begin{abstract}
ABST
Alanine uptake into liver plasma membrane vesicles was
studied at different stages of postnatal rat development. Before weaning, alanine hepatic uptake showed lower values for the global $\mathrm{K}_{\mathrm{M}}$ than after weaning $(0.34,0.77,1.45$, and $1.61 \mathrm{mM}$ for 1 -, 15-, and 28-d-old and adult rats, respectively). Alanine uptake capacity increased progressively until reaching maximum values in the adult state (values for $\mathrm{V}_{\text {max }}: 0.078,0.199,0.317$, and 0.613 nmol alanine/mg protein/3 s for 1-, 15-, and 28-d-old and adult rats, respectively). These results seem to point to a prevalence of a high affinity, low capacity alanine transport component (traditionally assumed to be attributable to system A) in newborn and suckling rats, in agreement with our previous results on isolated
\end{abstract}

Amino acid transport and utilization during postnatal development have not been extensively studied in spite of their role in sustaining growth. Amino acids are mainly used for anabolic purposes, such as protein accretion (1) with rates even higher than in the adult (2-4) or purine and pyrimidine biosynthesis (5). Moreover, typical gluconeogenic amino acids such as alanine play only a minor part as substrates for glucose production along the whole suckling period $(1,6)$. This lack of information is particularly noticeable regarding the sucklingweaning developmental transition, a period of trascendental metabolic changes in which carbohydrate and lipid metabolism are very well studied (7-9). Furthermore, most of the studies on amino acid transport during development have been performed on cultured hepatocytes from protease-treated livers (10-12), with some controverted results. Different approaches applied to amino acid transport during development are quite scarce (13). Recently, we have reported the kinetic study of alanine transport in freshly isolated hepatocytes from rat fetuses and neonates by a less injurious methodology (14). In that report, it was shown that, in fetal and neonatal hepatocytes,

Received August 23, 1994; accepted January 23, 1995.

Correspondence: Dr. Marçal Pastor-Anglada, Unitat de Bioquímica i Biologia Molecular B, Departament de Bioquímica i Fisiologia, Universitat de Barcelona, Avda Diagonal, 6456 planta, 08028 Barcelona, Spain.

Supported by grants PM90-0162 and PB92-0867 from the Dirección General de Investigación Científica y Tecnológica (DGICYT), Ministerio de Educación y Ciencia, Spain, and by the Nestlé Nutrition Research Grant Programme. hepatocytes (Martínez-Mas JV, Casado J, Felipe A, Marin JJG, Pastor-Anglada M: Biochem J 293: 819-824, 1993). The suckling-weaning developmental transition seems to play a role in establishing the pattern of adult hepatic alanine transport characterized by a higher capacity but a lower affinity (because most alanine is taken up by system ASC) inasmuch as $\mathrm{K}_{M}$ values show a $100 \%$ increase after weaning, although $\mathrm{V}_{\max }$ values continue to increase steadily until the adult age. (Pediatr Res 38: 81-85, 1995)
Abbreviation
MeAIB, $N$-(methylamino)isobutyric acid

there is a preeminence of alanine transport by a high affinity, low capacity agency that seems well established at these developmental stages. In the present study, we use liver plasma membrane vesicles to characterize the kinetics of alanine uptake during postnatal development, specially stressing the suckling-weaning developmental transition. Our conclusions corroborate that our previous results (14) are the reflection of the stable effects on the membrane.

\section{METHODS}

Animals. Female Wistar rats (200 g) from the Animal House of the University of Barcelona were kept under standard conditions and individually mated. Neonates were used between 12 and $24 \mathrm{~h}$ after birth, without discriminating between sexes. All other animals used were females. Suckling pups were used $15 \mathrm{~d}$ after birth, and weaned animals were used 28 $\mathrm{d}$ after birth (weaned on $\mathrm{d} 21$ ). Sixty-day-old female rats were used as adult controls. Body and liver weight and liver protein contents of all four groups are presented in Table 1 .

Purification of plasma membrane vesicles. Liver plasma membrane vesicles from neonatal, suckling, weaned, and adult animals were purified by a Percoll density gradient method as previously described (15). All preparations were assayed for proteins (16) and different enzyme markers to assess the degree of purification of plasma membrane fractions and the contamination by other subcellular membranes: $5^{\prime}$-nucleotidase (EC 
Table 1. Body and liver weights and hepatic protein contents

\begin{tabular}{lrcc}
\hline \multicolumn{1}{c}{ Rat } & $\begin{array}{c}\text { Body weight } \\
(\mathrm{g})\end{array}$ & $\begin{array}{c}\text { Liver weight } \\
(\mathrm{g})\end{array}$ & $\begin{array}{c}\text { Liver protein } \\
(\mathrm{mg} / \mathrm{g} \text { liver })\end{array}$ \\
\hline Newborn & $6.9 \pm 0.4$ & $0.26 \pm 0.01$ & $230 \pm 18$ \\
Suckling & $29.9 \pm 0.9$ & $0.87 \pm 0.03$ & $220 \pm 11$ \\
Weaned & $66.8 \pm 2.0$ & $2.61 \pm 0.11$ & $192 \pm 11$ \\
Adult & $194.9 \pm 3.1$ & $7.98 \pm 0.32$ & $225 \pm 9$ \\
\hline
\end{tabular}

Body weight, liver weight, and liver protein contents in all four experimental groups. Results are mean \pm SEM of six to 10 animals. Body and liver weights are the result of individual measurements. Hepatic protein contents are mean values for every litter, except for adult animals that are also individual values.

3.1.3.5) as plasma membrane marker, assayed as described by Lin and Morales (17); glucose-6-phosphatase (EC 3.1.3.9) as endoplasmic reticulum membrane marker, assayed as in Baginski et al. (18); $N$-Acetyl- $\beta$-glucosaminidase (EC 3.2.1.52) as lysosomal membrane marker, determined as in Caroll (19); and succinate dehydrogenase (EC 1.3.99.1), a mitochondrial marker, assayed as shown by Bonner (20).

Uptake measurements. Amino acid transport into the inner vesicular space was measured by a filtration procedure adapted from Sips et al. (21) and Pastor-Anglada et al. (15). The incubation medium consisted of $0.25 \mathrm{M}$ sucrose, $0.2 \mathrm{mM}$ $\mathrm{CaCl}_{2}, 10 \mathrm{mM} \mathrm{MgCl}, 10 \mathrm{mM} \mathrm{N}$-2-hydroxyethylpiperazine$N^{\prime}$-2-ethanesulfonic acid/KOH, $\mathrm{pH}=7.4,100 \mathrm{mM} \mathrm{NaSCN}$ or KSCN and $\mathrm{L}-\left[2,3-{ }^{3} \mathrm{H}\right]$ alanine (Amersham Corp.) at different concentrations and specific activities depending on the characteristics of each experiment. Transport was measured at $15^{\circ} \mathrm{C}$, to improve measurements of initial velocities over the classical method at $25^{\circ} \mathrm{C}$ (data not shown). Alanine uptake inhibitable by excess concentrations of MeAIB was determined as a measure of system A activity.

Calculation of the kinetic parameters. Kinetic constants of the $\mathrm{Na}^{+}$-dependent uptake of alanine were derived mathematically from the experimental data by nonlinear regression analysis using FigP software (FigP Software Corp., Durham, $\mathrm{NC}$ ). Kinetic analysis was always done in triplicate on plasma membrane fractions from four to six single purifications. The results are mean \pm SEM of the kinetic parameters calculated for every rat liver.

Blood alanine levels. In 15- and 28-d-old and adult female rats, portal alanine levels were also measured. Four to six animals per group were anesthetized by an intraperitoneal pentobarbital injection $(60 \mathrm{mg} / \mathrm{kg}$ body weight), and blood samples were withdrawn from the portal vein using heparinized syringes. Alanine was determined by a standard enzymatic spectrophotometric method (22), and results are given as mean \pm SEM.

\section{RESULTS}

Characterization of plasma membrane preparations. The recoveries and relative specific activities (enrichments) of $5^{\prime}$ nucleotidase, the plasma membrane enzyme marker, are shown in Table 2. Recoveries are given as the percentage of initial homogenate activities found in final preparations. Enrichments are the ratios of enzyme specific activity in the membrane preparation to the specific activity in the homogenate. 5'Nucleotidase enrichments were similar in all groups except in
Table 2. Characterization of plasma membrane vesicle preparations

\begin{tabular}{ccc}
\hline & \multicolumn{2}{c}{$5^{\prime}$-Nucleotidase } \\
\cline { 2 - 3 } Rat & Recovery & Enrichment \\
\hline Newborn & $7.3 \pm 1.2$ & $9.3 \pm 2.0^{*}$ \\
Suckling & $5.0 \pm 0.8$ & $4.2 \pm 0.7$ \\
Weaned & $8.8 \pm 0.7$ & $4.5 \pm 0.4$ \\
Adult & $6.6 \pm 1.2$ & $4.3 \pm 0.5$ \\
\hline
\end{tabular}

$5^{\prime}$-Nucleotidase (plasma membrane marker) recoveries and enrichments. Recoveries are given as percentage of initial homogenate activities. Enrichments are the ratio of specific activity in the plasma membrane fraction to the activity in the initial homogenate. Each point is the mean \pm SEM of four to six independent preparations. Statistical comparison by a $t$ test.

$* p<0.05$ vs adult.

neonatal preparations in which it was significantly higher. Contamination by other subcellular membranes (microsomal, mitochondrial, lysosomal) were in the range previously described (23-26). Apparent vesicular volumes were $530 \pm 65$, $320 \pm 73,255 \pm 12$, and $220 \pm 11 \mathrm{~nL} / \mathrm{mg}$ protein for newborn, suckling, weaned, and adult animals, respectively. Statistical differences were found between newborn and adult rats ( $p<0.001$, Student's $t$ test).

Kinetics of L-alanine transport. In the absence of an inward transmembrane sodium gradient $\left(\mathrm{K}^{+}\right.$medium), $\mathrm{L}$-alanine uptake by plasma membrane vesicles in all groups increased steadily with alanine concentrations, and it was assumed to represent simple diffusion, because no saturability was observed. Diffusion coefficients $\left(\mathrm{K}_{\mathrm{d}}\right)$ were quite similar in all groups and only slightly higher in the neonatal preparations (Table 3). When the diffusion component was substracted from the whole $\mathrm{L}$-alanine transport in the $\mathrm{Na}^{+}$medium, a $\mathrm{Na}^{+}$dependent, saturable component emerged. This component is presented in Figure 1, showing a classical hyperbolic behavior of initial rates as alanine concentrations increase. The kinetic parameters of this component $\left(\mathrm{K}_{\mathrm{M}}\right.$ and $\left.\mathrm{V}_{\text {max }}\right)$ for all the groups are given in Table 3 and their evolution along development is presented in Figure 2. Plasma membrane vesicles from newborn rats showed much lower values of both $\mathrm{K}_{\mathrm{M}}$ and $\mathrm{V}_{\max }$ than the adults. The evolution of $K_{M}$ during development is strictly paralleled by the evolution of portal blood alanine concentrations (Fig. 3), showing a perfect linear correlation coefficient between them ( $r=1.00$, Fig. 4). Both parameters showed a sharp increase around weaning (Figs. 3 and 4). On the other hand, $V_{\max }$ values seemed to be a simple function of time, showing no particular feature around the suckling-weaning

Table 3. Kinetic parameters of hepatic alanine transport

\begin{tabular}{llll}
\hline \multicolumn{1}{c}{ Rat } & \multicolumn{1}{c}{$\mathrm{V}_{\max }$} & \multicolumn{1}{c}{$\mathrm{K}_{\mathrm{M}}$} & \multicolumn{1}{c}{$\mathrm{K}_{\mathrm{d}}$} \\
\hline Newborn & $0.078 \pm 0.003^{* * *}$ & $0.34 \pm 0.07^{* *}$ & $0.146 \pm 0.017$ \\
Suckling & $0.199 \pm 0.009^{* * *} \uparrow$ & $0.77 \pm 0.13^{*,} \uparrow$ & $0.092 \pm 0.10$ \\
Weaned & $0.317 \pm 0.025^{* *}$ & $1.45 \pm 0.25$ & $0.075 \pm 0.013$ \\
Adult & $0.613 \pm 0.069$ & $1.61 \pm 0.33$ & $0.110 \pm 0.030$ \\
\hline
\end{tabular}

Kinetic parameters for the $\mathrm{Na}^{+}$-dependent component $\left(\mathrm{K}_{\mathrm{M}}\right.$ and $\left.\mathrm{V}_{\text {max }}\right)$ and diffusion $\left(\mathrm{K}_{\mathrm{d}}\right)$ of alanine transport. $\mathrm{K}_{\mathrm{M}}$ is given in millimolar, $\mathrm{V}_{\max }$ is given in nanomoles of alanine per $\mathrm{mg}$ of protein $3 \mathrm{~s}$ and $\mathrm{K}_{\mathrm{d}}$ is given in nanoliters $/ 3$ $\mathrm{s} / \mu \mathrm{g}$ of protein. Each point is the mean $\pm \mathrm{SEM}$ of four to six independent preparations. Statistical comparisons by a $t$ test are as follows: ${ }^{*} p<0.05 ;{ }^{* *} p$ $<0.01 ;{ }^{* *} p<0.001$ vs adult. $\dagger p<0.05 ; \ddagger p<0.01$, suckling $v s$ weaned. 

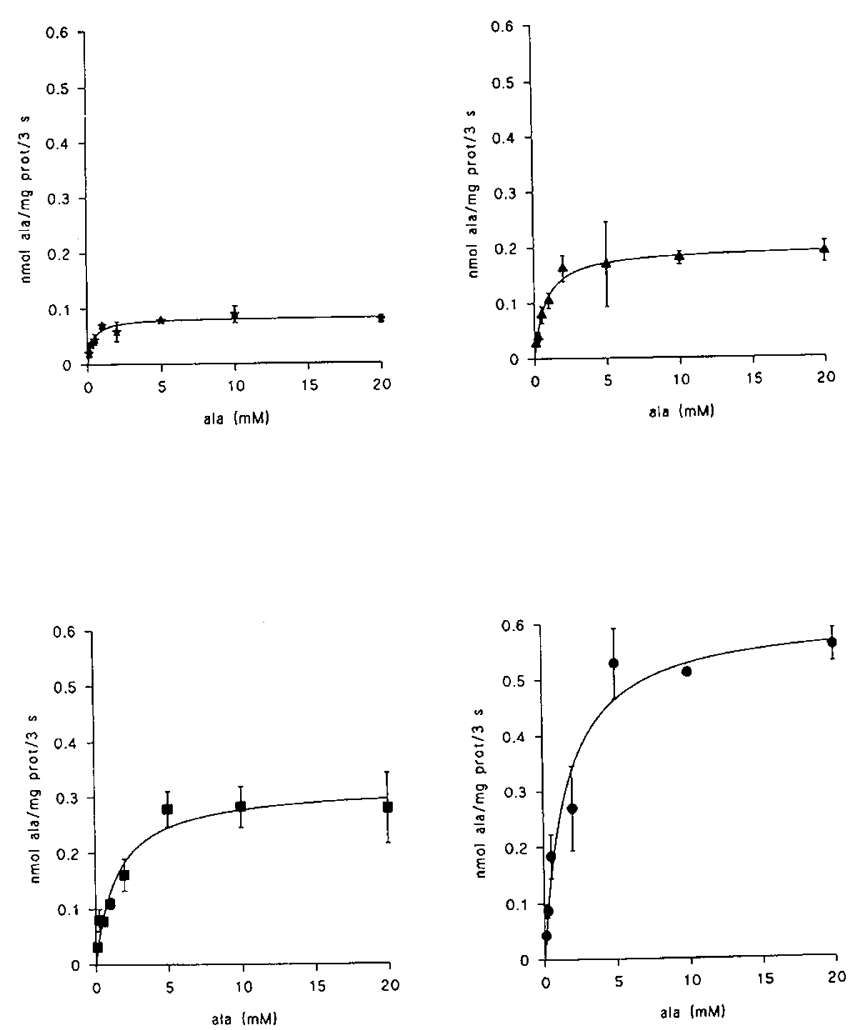

Figure 1. Substrate concentration dependence of the $\mathrm{Na}^{+}$-dependent component of alanine transport: upper left, newborn rats; upper right, suckling rats; lower left, weaned rats; lower right, adult rats. Each point is the mean $\pm \mathrm{SEM}$ of four to six independent preparations. All panels are drawn at the same scale for easy comparison between groups.

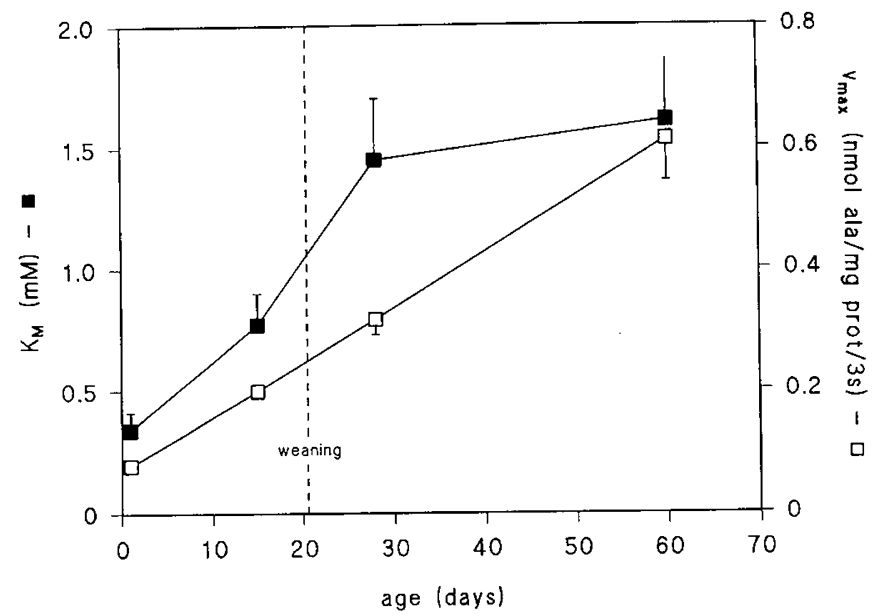

Figure 2. Evolution of kinetic parameters $\left(\mathrm{K}_{\mathrm{M}}, \mathbf{\square} ; \mathrm{V}_{\max }, \square\right)$ during development. Although $V_{\max }$ values seem to be only a function of time, $\mathrm{K}_{\mathrm{M}}$ adult values have already been reached immediately after weaning.

transition (Fig. 2) and a much lower lineal correlation coefficient with portal alanine levels $(r=0.82$, Fig. 4). The contribution of transport systems A and ASC to total sodium dependent alanine uptake in suckling, weaned and adult rats is shown in Table 4. At all conditions tested, the contribution of system A (MeAIB-sensitive, $\mathrm{Na}^{+}$-dependent alanine transport) to the overall alanine uptake was much higher in rat pups that in the adults, although we could not detect significant differences in

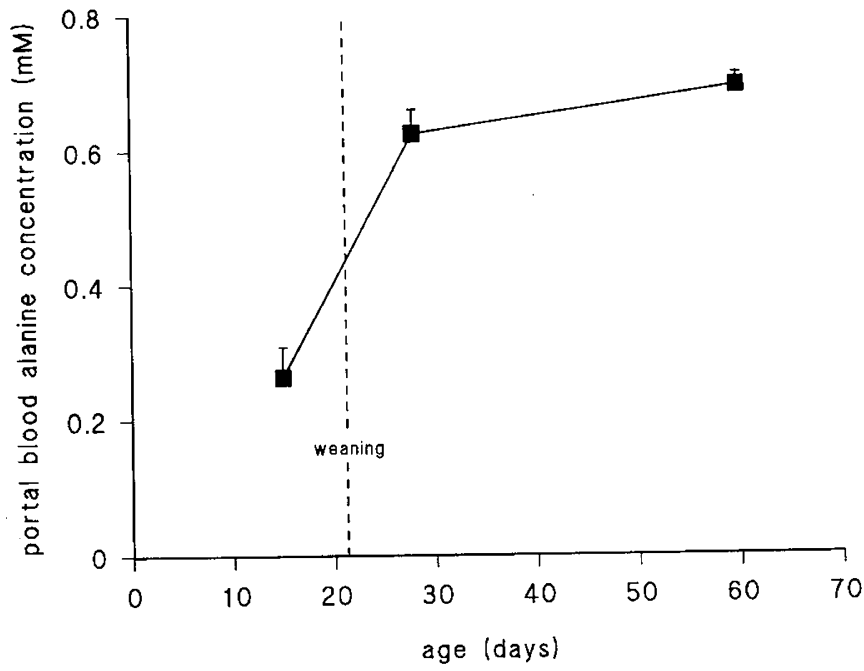

Figure 3. Evolution of portal blood alanine concentrations during development. Results are mean \pm SEM of four to six individual determinations.

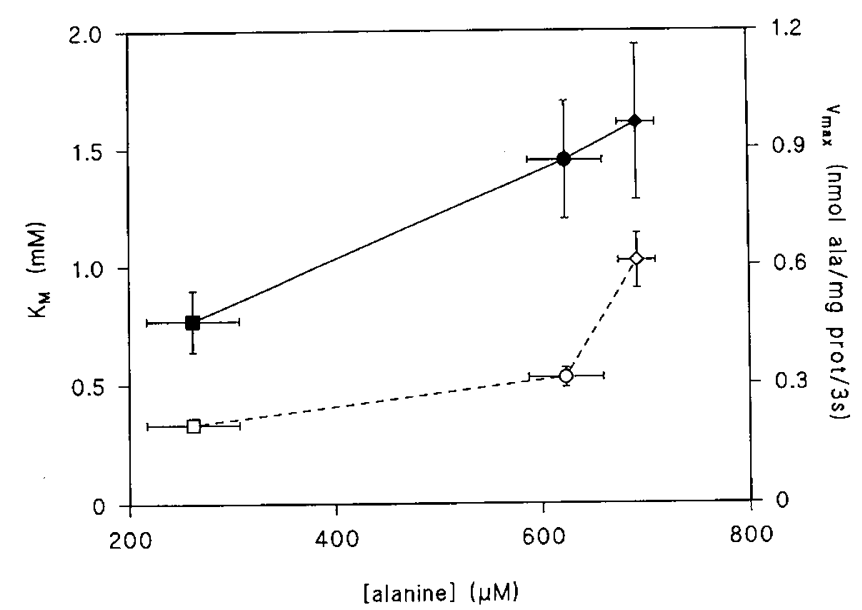

Figure 4. Correlation between alanine portal blood levels and either $K_{M}$ (closed symbols) or $\mathrm{V}_{\max }$ (open symbols) values during development $(\square, \mathbf{\square}$, suckling; $\bigcirc, \odot$, weaned; $\diamond, \diamond$, adult). Lineal correlation coefficients: $r=1.00$ for $\mathrm{K}_{\mathrm{M}}$ and alanine concentrations; $r=0.82$ for $\mathrm{V}_{\max }$ and alanine concentrations.

absolute terms. System ASC activity (MeAIB-resistant, $\mathrm{Na}^{+}$dependent alanine transport), however, was higher in adult than in suckling and weaned rats.

\section{DISCUSSION}

Plasma membrane vesicles are useful in studies comparing different physiologic situations provide that physical properties of vesicles are similar among the various situations. Thus, they have been used to study such situations as short-term fasting (24), pregnancy (26), diabetes (27), suckling (28), or obesity (29). In the present work, all groups of vesicles had similar physical properties, with the exception of plasma membrane vesicles from neonates. Vesicles from this group presented a higher $5^{\prime}$-nucleotidase enrichment, a slightly higher (although not statistical) diffusion coefficient and also a higher intravesicular volume, in accordance with other reports (13); all these data taken together point toward a somehow different composition of the plasma membranes of rat liver parenchymal cells 
Table 4. Contribution of transport systems A and ASC to total $\mathrm{Na}^{+}$-dependent alanine uptake

\begin{tabular}{|c|c|c|c|c|}
\hline \multirow[b]{3}{*}{ Rat } & \multicolumn{4}{|c|}{ L-Alanine concentration } \\
\hline & \multicolumn{2}{|c|}{$0.5 \mathrm{mM}$} & \multicolumn{2}{|c|}{$1 \mathrm{mM}$} \\
\hline & A & ASC & A & ASC \\
\hline Suckling & $76 \pm 8(88 \%)$ & $10 \pm 1(12 \%)$ & $119 \pm 21(98 \%)$ & $3 \pm 0(2 \%)$ \\
\hline Weaned & $59 \pm 11(82 \%)$ & $13 \pm 1(18 \%)$ & $102 \pm 7(94 \%)$ & $7 \pm 0(6 \%)$ \\
\hline Adult & $66 \pm 10(59 \%)$ & $45 \pm 9(41 \%)$ & $108 \pm 30(66 \%)$ & $56 \pm 10(34 \%)$ \\
\hline
\end{tabular}

System A activity (MeAIB-sensitive, $\mathrm{Na}^{+}$-dependent alanine uptake) and system ASC activity (MeAIB-resistant, $\mathrm{Na}^{+}$-dependent alanine uptake) were measured to assess the contribution of each transport agency to total $\mathrm{Na}^{+}$. dependent alanine uptake at three physiologic alanine concentrations. MeAIB was used at a concentration of $25 \mathrm{mM}$. Results are expressed as picomoles of alanine $/ 3 \mathrm{~s} / \mathrm{mg}$ of protein. Values are means \pm SEM of triplicate measurements from three to four different vesicle preparations.

shortly after birth compared with the adult state. These differences would make difficult to compare the results of plasma membrane vesicles from rat neonates with those from the other groups. Nevertheless, they do not imply a loss of significance in the statistical comparisons because all the differences in the plasma membrane physical properties suggest a certain overestimation of L-alanine transport rates in the newborn preparations. Vesicles with larger volumes will show a higher alanine concentrative capacity, which will result in apparent higher transport kinetic parameters, especially if there is also a greater diffusion. So, the actual differences with the adult preparations would be even higher than those here reported. Besides, these differences on alanine transport capacity are to be due to intrinsic differences between alanine transport agencies in neonates and those in the other groups, because sodium gradient dissipation rate seems not to be increased in neonatal plasma membrane vesicles (13).

Alanine is mainly transported into the parenchymal liver cell by two different agencies: a high affinity, low capacity system (assimilated to system A) and a low affinity, high capacity one (assumed to be system ASC) (30). Our results suggest that the high affinity agency would be already established by the time of birth, in concordance with our previous report on isolated hepatocytes (14) and with the results of Leoni et al. (12), who found a high fetal system A activity in rat liver that progressively declined during the perinatal period to the lower values of the adult. This could be understood as an adaptation to secure that the high hepatocyte amino acid requirements will be met in a situation in which portal amino acid concentrations are relatively low (31). Not only system A shows a higher affinity for amino acid transport but it is also responsive to the drop in blood amino acid levels occurring after birth that would release hepatocytes from any trans-inhibiting effect allowing a higher alanine transport rate $(10,32)$. This postnatal system $\mathrm{A}$, unlike the one in the adult rat, is mostly unresponsive to insulin $(32,33)$, in agreement with the generalized state of insulin resistance of this age $(34,35)$. So liver amino acid supply would not be altered by changes in insulin concentrations.

The suckling-weaning nutritional and developmental transition is characterized by important nutritional (36), hormonal (7), and metabolic changes affecting both carbohydrate $(8,9$, $37)$ and lipid metabolism $(8,9,38)$. This nutritional breakpoint seems to play a key role in the evolution of alanine transport into the parenchymal liver cell, because the apparent $K_{M}$ for this uptake is sharply increased immediately after weaning. This result can be considered as reflecting the moment in which the high capacity, low affinity agency described in hepatocytes (14) would become the main alanine transport system in these cells. This would be physiologically consistent, because blood alanine concentration after weaning has reached normal adult values and hepatic amino acid requirements are lower and more easily met. However, the functionality of this system is not perfectly established immediately after weaning, because $\mathrm{V}_{\max }$ values grow steadily until the adult state. In agreement with this point, system ASC activity is lower in weaned than in adult rats at the concentrations tested (all in the physiologic range), but there is a tendency, although not statistically significant, to be higher than in suckling rats. An alternative explanation for the different ASC activities found between adult and developing rats might be a different degree of canalicular membrane contamination in the preparations from each group. Thus, because ASC activity has been localized mostly in the canalicular membrane (39), a higher ASC activity in the adult preparations could reflect only a higher contamination by the canalicular membrane fraction. Although canalicular contamination is present to some extent in our preparations (40), such an explanation does not seem likely, because differences in high capacity, low affinity alanine uptake among these three developmental stages have been reported also in isolated hepatocytes (14), where this problem would not be present.

In conclusion, hepatic alanine uptake shows a lower capacity and higher affinity right after birth compared with the adult state. Such a metabolic feature seems appropriate for the developing liver to ensure its amino acid supply in a context of relatively low portal availability. The suckling-weaning developmental transition reflects a sharp increase in the $K_{M}$ value for hepatic alanine uptake, which could be considered as the shift toward the adult system for neutral amino acid transport in the liver.

\section{REFERENCES}

1. Snell K 1982 Protein, amino acid and urea metabolism in the neonate. In: Jones CT (ed) Biochemical Development of the Fetus and the Neonate. Elsevier Biomedical Press, Amsterdam, pp 651-695

2. Goldspink DF, Kelly FJ 1984 Protein turnover and growth in the whole body, liver and kidney of the rat from the foetus to senility. Biochem J 217:507-516

3. Goldspink DF, Lewis SEM, Kelly FJ 1984 Protein synthesis during the developmental growth of the small and large intestine of the rat. Biochem J 217:527-534

4. Lewis SEM, Kelly FJ, Goldspink DF 1984 Pre- and postnatal growth and protein turnover in smooth muscle, heart and slow- and fast-twitch skeletal muscles of the rat. Biochem J 217:517-526

5. Jones CT, Rolph TP 1985 Metabolism during fetal life: A functional assessment of metabolic development. Physiol Rev 65:357-430

6. Snell K 1981 Regulation of protein metabolism during postnatal development Biochem Soc Trans 9:367-368

7. Issad T, Coupé C, Ferré P, Girard J 1987 Insulin resistance during suckling period in rats. Am J Physiol 253:E142-E148

8. Challiss RAJ, Ferré P 1988 Integration of carbohydrate and lipid metabolism in skeletal muscle during postnatal development. Reprod Nutr Dev 28:805-815

9. Issad T, Ferré P, Pastor-Anglada M, Baudon MA, Girard J 1989 Development of insulin sensitivity in the white adipose tissue during the suckling-weaning transition in the rat. Involvement of glucose transport and lipogenesis. Biochem J 264:217-222

10. Belleman P 1981 Enhanced amino acid transport in cultured hepatocytes during liver development. J Biochem 90:1821-1824

11. Belleman P 1981 Amino acid transport and rubidium-ion uptake in monolayer cultures of hepatocytes from neonatal rats. Biochem J 198:475-483 
12. Leoni S, Spagnuolo S, Dini L, Conti Devirgilis L 1987 Regulation of amino acid transport in isolated rat hepatocytes during development. J Cell Physiol 130:103-110

13. Suchy FJ, Bucuvalas JC, Goodrich AL, Moyer MS, Blitzer BL 1986 Taurocholate transport and $\mathrm{Na}^{+}-\mathrm{K}^{+}$-ATPase activity in fetal and neonatal rat liver plasma mebrane vesicles. Am J Physiol 251:G665-G673

14. Martínez-Mas JV, Casado J, Felipe A, Marin JJG, Pastor-Anglada M 1993 L-Alanine uptake by rat liver parenchymal and hematopoietic cells during the perinatal period. Biochem J 293:819-824

15. Pastor-Anglada M, Remesar X, Bourdel G 1987 Alanine uptake by liver at midpregnancy in rats. Am J Physiol 252:E408-E413

16. Peterson GL 1979 Review of the Folin phenol protein quantitation method of Lowry, Farr and Randall. Anal Biochem 100:201-220

17. Lin TI, Morales MF 1977 Application of one-step procedure for measuring inorganic phosphate in the presence of proteins: The actomyosin ATPase system. Anal Biochem 77:10-17

18. Baginski ES, Foa PP, Zack B 1986 Glucose-6-phosphatase. In: Bergmeyer HU (ed) Methods of Enzymatic Analysis. Academic Press, New York, pp 876-880

19. Carroll M 1978 Characterization of protein structurally related to human $\mathrm{N}-\beta$ D-glucosaminidase. Biochem J 173:191-196

20. Bonner WD 1955 Succinic dehydrogenase. Methods Enzymol 1:722-729

21. Sips HJ, Van Amelsvoort JMM, Van Dam K 1980 Amino acid transport in plasma membrane vesicles from rat liver. Characterization of L-alanine transport. Eur Biochem 105:217-224

22. Williamson DH 1986 L-Alanine. Determination with alanine dehydrogenase. In: Bergmeyer HU (ed) Methods of Enzymatic Analysis. Academic Press, New York, pp $1679-1682$

23. Van Amelsvoort JMM, Sips HJ, Van Dam K 1978 Sodium-dependent alanine transport in plasma-membrane vesicles from rat liver. Biochem J 174:1083-1086

24. Bourdel G, Forestier M 1982 Circadian variations of A-mediated transport in rat-live plasma membrane vesicles. FEBS Lett 143:81-85

25. Quintana I, Felipe A, Remesar X, Pastor-Anglada M 1988 Carrier-mediated uptake of L- $(+)$-lactate in plasma membrane vesicles from rat liver. FEBS Lett 235:224-228

26. Felipe A, Remesar X, Pastor-Anglada M $1989 \mathrm{Na}^{+}$-Dependent alanine transport in plasma membrane vesicles from late-pregnant rat livers. Pediatr Res 26:448-451

27. Rosenthal NR, Jacob R, Barrett E 1985 Diabetes enhances activity of alanine transport in liver plasma membrane vesicles. Am J Physiol 248:E581-E587
28. Casado J, Felipe A, Pastor-Anglada M, Remesar X 1988 Glutamine as a major nitrogen carrier to the liver in suckling rat pups. Biochem $J$ 256:377-381

29. Ruiz B, Felipe A, Casado J, Pastor-Anglada M 1991 Amino acid uptake by liver of genetically obese Zucker rats. Biochem J 280:367-372

30. Guidotti GC, Borghetti AF, Gazzola GC 1978 The regulation of amino acid transport in animal cells. Biochim Biophys Acta 737:267-284

31. Christensen HN, Clifford JB 1963 Early postnatal intensification of hepatic accumulation of amino acids. J Biol Chem 238:1743-1745

32. Handlogten M, Kilberg MS 1982 Transport system A is not responsive to hormona stimulation in primary cultures of fetal rat hepatocytes. Biochem Biophys Res Commun 108:1113--1118

33. Riggs TR, Wise KD, Motz KL 1978 Amino acid transport in diaphragm of newborn rats. Evidence for insulin resistance. Am J Physiol 235:E304-E310

34. Autori F, Baldini P, Ciofi Luzzato A, Dini L, Incerpi S, Luly P 1981 Insulin binding and internalization in rat hepatocytes during prenatal and postnatal life. Biochim Biophys Acta 678:1-6

35. Caliendo AM, Patel MS 1983 Insulin receptor in developing rat liver: acquisition of down regulation in the immediate postnatal period. Arch Biochem Biophys 227:552561

36. Issad T, Coupé C, Pastor-Anglada M, Ferré P, Girard J 1988 Development of insulin-sensitivity at weaning in the rat. Role of the nutritional transition. Biochem J 251:685-690

37. Issad T, Pastor-Anglada M, Coupé C, Ferré P, Girard J 1990 Glucose metabolism and insulin sensitivity during the suckling period in rats. In: Cuezva JM, Pascual-Leone AM, Patel MS (eds) Endocrine and Biochemical Development of the Fetus and the Neonate. Plenum Press, New York, pp 61-66

38. Taylor CB, Bailey E, Bartley W 1967 Changes in hepatic lipogenesis during development of the rat. Biochem J 105:717-722

39. Meier PJ, St. Meier-Abt A, Barret C, Boyer JL 1984 Mechanisms of taurocholate transport in canalicular and basolateral rat liver plasma membrane vesicles. Evidence for an electrogenic canalicular organic anion carrier. J Biol Chem 259:10614-10622

40. Ruiz-Montasell B, Martínez-Mas JV, Enrich C, Casado FJ, Felipe A, Pastor-Anglad M 1993 Early induction of $\mathrm{Na}^{+}$-dependent uridine uptake in the regenerating rat liver FEBS Lett 316:85-88 